\title{
Scalping degloving foot injury as a difficult therapeutic problem
}

\author{
Tomasz Kulesza', Leszek Jankiewicz', Jacek Sompor' ${ }^{1}$, Andrzej Prystupa ${ }^{2}$ \\ ${ }^{1}$ Department of Traumatology and Emergency Medicine, Medical University, Lublin, Poland \\ ${ }^{2}$ Department of Internal Medicine, Medical University, Lublin, Poland
}

Kulesza T, Jankiewicz L, Sompor J, Prystupa A. Scalping degloving foot injury as a difficult therapeutic problem. J Pre-Clin Clin Res. 2013; $7(1): 63-65$.

\section{Abstract}

The case is presented of a rare case of scalping foot injury of the degloving type, treated at the Clinic of Traumatology and Emergency Medicine at the Medical University in Lublin, Poland. The successful treatment used the simplest reconstructive technique involving the utilization of an intermediate thickness skin graft, which was taken from the detached skin of the feet. This technique should be taken into consideration in this era of using new and sophisticated methods of treating physical defects.

\section{Key words \\ scalping, degloving, foot injury}

\section{INTRODUCTION}

Serious complex injuries of the lower limbs still remain a great challenge for surgeons. Among them, special attention is needed for injuries with extensive, scalping detachment of skin, known as 'degloving' in English literature. Injuries of this type can be defined as avulsive-abrasive detachment of skin from the underlying fascia, muscle and bone tissue, which causes damage to blood vessels supplying the skin $[1,2,3]$. They are most frequently caused by complex abrasive, compressive and tearing deforming forces which are transmitted to the limbs during high energy trauma in traffic, agricultural and industrial accidents. Injuries of this type interrupt large vessels and damage the capillary network of the subcutaneous tissue. The resulting swelling and haematoma cause the detached skin to move away from the deeper underlying tissue which affects the formation of ischaemia [2].

The aim of this study was to present a patient who suffered a rare scalping degloving foot injury.

\section{CASE REPORT}

A steelworker was injured after his foot was caught in moving conveyor belt rollers. As a result of the trauma, the patient suffered total scalping of the foot without metatarsal and tarsal fractures (Fig. 1). The skin in the subcutaneous tissue layer was torn off, exposing the fascia, and delivered with the patient without being cooled during transportation. The limb was rated 5 points on the MESS scale [4]. Surgery was performed as a matter of urgency. Surgical toilet of the wounds with the necessary amputation of the distal phalanges of the toes due to the total exposure of bone was performed. Grafts of intermediate thickness were taken from the detached foot skin of both dorsal and plantar surfaces and sutured in the defect. In this way, the entire wound was

Address for correspondence: Andrzej Prystupa, Department of Internal Medicine Medical University, Staszica 16, 20-081 Lublin, Poland

e-mail: aprystupa@mp.pl

Received: 19 October 2012; accepted: 29 December 2012

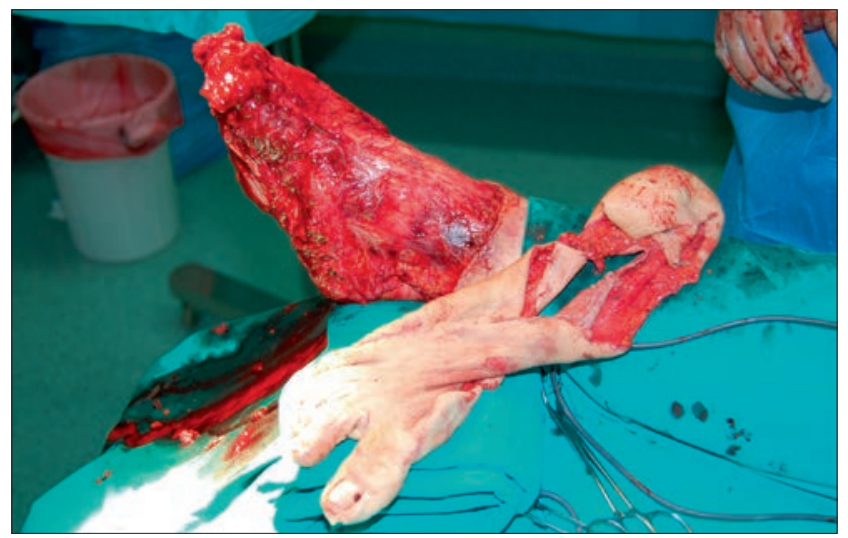

Figure 1. The total scalping of the foot after trauma.

covered. Grafts taken from the plantar surface were sutured on the sole side. The first dressing was changed on the 3rd day after surgery. The graft was incorporated into $80 \%$ of the surface of the wound. Foot and crurotalar articulation were fixed with an external fixator on the 7th day because of club foot deformation (Fig. 2). The external fixator was removed after 6 weeks. The patient began to put weight on the foot. He now wears normal shoes with forefoot filling. Ankle movements are restricted, but no consistent faulty setting

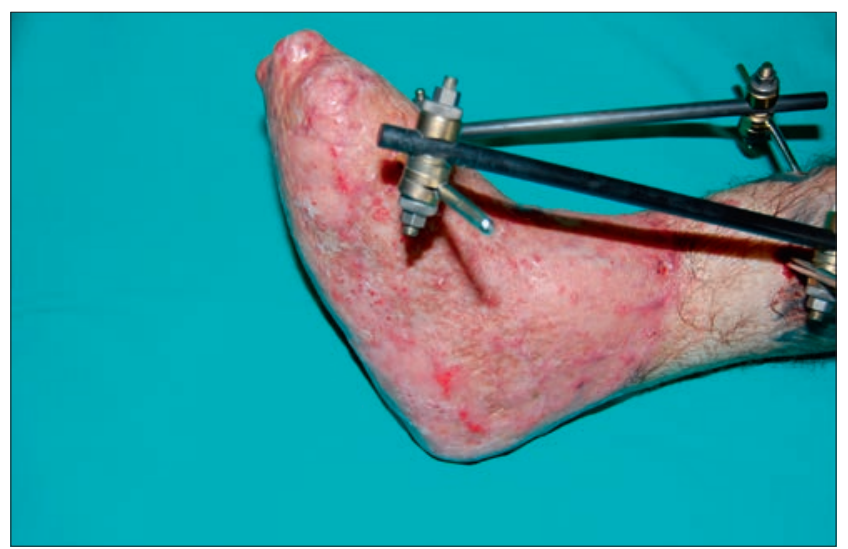

Figure 2. The foot and crurotalar articulation fixed with external fixator. 


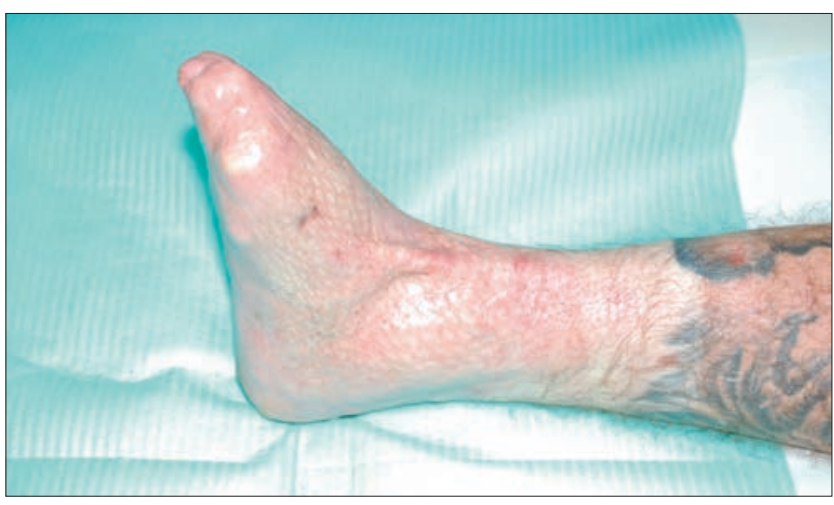

Figure 3. The foot after treatment.

of the foot is observed. The patient returned to work at a different job and is satisfied with the effect of the treatment (Fig. 3).

\section{DISCUSSION}

Lower limb with injury of the 'degloving' type must be accessed according to the MESS (Mangled Extremity Severity Score) scale, proposed in 1990 by Johansen [4]. Injuries of this type are caused by the action of high-energy trauma. The MESS scale allows accurate prediction of the need for primary amputation when the score is higher than or equal to 7 , and the possibility of saving the limb when the score is lower than or equal to 6 [4]. As the patient's limb was rated 5 points on the MESS scale, amputation was not considered, especially since deep sensation was retained on the plantar side of the foot.

When treating patients with skin detachment injuries, the main difficulty is assessing the viability of detached skin, which is essential for its survival. Different ways of measuring blood supply to the skin may be found in literature. Methods consisting of examining the appearance, warming, bleeding edge and vascular game are the simplest [3]. These subjective methods are often unreliable; therefore, observing the skin in ultraviolet light after intravenous administration of fluorescein is proposed. An intense glowing of the skin meant good blood perfusion [3]. There have been reports of adverse effects from the dye on the organism $[5,6]$. Monitoring of $\mathrm{pH}$ and oxygen saturation of blood flowing through the patches of skin at risk of necrosis proved to be very promising [7, 8]. Doppler test is more widely used in the evaluation of blood flow intensity in skin at risk $[9,10]$. In 1997 , Wajkakul proposed using observation of subcutaneous vein thrombosis to evaluate skin demarcation, and on this basis forecasting the possibility of its subsequent arterialization [11]. A shaving test, consisting of taking thin grafts from detached skin with dermatome, was also used to assess skin protrusion. Spot bleeding from the tissues was used as an indicator of tissue viability [12]. There were reports of the use of indocyanine green angiography in assessing the patency of the skin vessels [13]. In the case in question, total interruption of communication of the skin with the fascia was found; therefore, skin viability assessment was simplified and based only on visual inspection and a scarification test.

Waikakul suggests dividing degloving injuries into groups: 1. includes very damaged skin patches from which fullthickness grafts are taken to cover the defects suffered [11].
2. consist of skin patches with medium damage separated from the fascia, which, according to the author, are eligible for venous-arterial vascular anastomosis.

The necessary pre-condition for surgery is the presence of broken veins in detached skin with retrograde outflow of blood. This revascularization, however, is only possible in selected cases, as secondary thrombosis in the vessels within the tissue breakage can be expected [11]. Arnez et al retrospectively reviewed a series of 79 complex limb injuries. The soft-tissue injuries were then described and revealed four patterns of injury [1].

type I - abrasion/avulsion;

type II - non-circumferential degloving;

type III - circumferential single plane;

type IV - circumferential multi-plane degloving.

Resuturing of degloved skin was only successful in noncircumferential (type 2) cases. Radical excision of devitalised tissue followed by soft-tissue reconstruction in a single procedure was successful in all types apart from type 4 (circumferential multi-plane degloving). In pattern 4 they recommended the serial excision of dead tissue prior to reconstruction using flaps or skin grafts [1]. The use of skin grafts in the treatment of degloved skin defects is a universally accepted method $[2,11]$. If after the injury detached skin is not damaged it is generally accepted that the degloved tissue should be excised, defatted, and reapplied as a full-thickness skin graft [2]. When the skin is completely degloved, grafts of intermediate thickness are taken from the skin before its removal and then used to cover the exposed tissue [2]. This method was also used in the presented case. A thicker graft on the plantar foot taken from degloved skin on the surface of the sole was applied. Grafts were placed on the fascia, and fatty tissue well supplied with blood, above the plantar aponeurosis of the foot.

A very effective method of treatment is the use of vacuum therapy, in particular for fixing sutured skin grafts [14]. This method reduces tissue swelling, reduces the number of bacteria, increases tissue perfusion and improves blood supply to the wound. This treatment was not used in the case reported, in which ordinary multilayer pressure dressing was applied.

Other methods of reconstruction, especially free flaps, should also be considered [15]. Free flaps are technically difficult and require a surgical team adequately trained for this type of intervention. For this reason, in the presented case the decision was made to use a simple method of treatment. The application of the free flap was considered as the secondary treatment in case of complications.

The damage described in the presented case is rare and the treatment used is the simplest, but an effective reconstructive technique involving the use of grafts of intermediate thickness taken from detached skin. This effective technique should not be forgotten in the era of the use of new and sophisticated methods of covering defects.

\section{REFERENCES}

1. Arnez ZM, Khan U, Tyler MPH. Classification of soft-tissue degloving in limb trauma. J Plast Reconstr Aesthet Surg. 2010; 63: 1865-69.

2. Antoniou D, Kyriakidis A, Zaharopoulos A et al. Degloving injury. Eur J Trauma. 2005; 6: 593-6.

3. Mandel MA. The management of lower extremity degloving injuries. Ann Plast Surg. 1981; 6: 1-5. 
4. Johansen K, Daines M, Howey T, et al. Objective criteria accurately predict amputation following lower extremity trauma. J Trauma. 1990; 30: $568-73$.

5. Graham BH, Gordon L, Alpert BS, et al. Serial quantitative skin surface fluorescence: a new method for postoperative monitoring of vascular perfusion in revascularized digits. J Hand Surg. 1985; 10: 226-30.

6. Casanova R, Iribarren O, Grotting JC, et al. Clinical evaluation of flap viability with a dermal surface fluorometer. Ann Plast Surg. 1988; 20: 112-6.

7. Serafin D, Lesesne CB, Mullen RY, et al. Transcutaneous $\mathrm{PO}_{2}$ monitoring for assessing viability and predicting survival of skin flaps: experimental and clinical correlations. J Microsurg. 1981; 2: 165-78.

8. Hirigoyen MB, Blackwell KE, Zhang WX, et al. Continuous tissue oxygen tension measurement as a monitor of free- flap viability. Plast Reconstr Surg. 1997; 99: 763-73.

9. Solomon GA, Yeremchuk MJ, Mansen PN. Doppler ultrasound surface monitoring of both arterial and venous flow in clinical free tissue transfers. J Reconstr Microsurg. 1986; 3: 39-41.
10. Jones BM, Mayou BJ. The laser Doppler flowmeter for microvascular monitoring: a preliminary report. Br J Plast Surg. 1988; 35: 147-9.

11. Waikakul S. Revascularisation of degloving injuries of the limbs. Injury 1997; 28: 271-4.

12.Ziv I, Zeligowski AA, Elyashuv O, et al. Immediate care of crush injuries and compartment syndromes with the split-thickness skin excision. Clin Orthop. 1990; 256: 224-8.

13. Kamolz LP, Andel H, Auer T, et al. Evaluation of skin perfusion by use of indocyanine green video angiography: rational design and planning of trauma surgery. J Trauma. 2006; 61: 635-41.

14. Josty IC, Ramaswamy R, Laing JHE. Vacuum assisted closure: an alternative strategy in the management of degloving injuries of the foot. Br J Plast Surg. 2001; 54: 363-5.

15. Swartz WM, Mears DC. The role of free-tissue transfers in lowerextremity reconstruction. Plast Reconstr Surg. 1985; 76: 364-73. 